\title{
Nutrition information noticed in restaurants if on menu
}

$\mathrm{L}$ ocation matters. It matters in business, in real estate and also, apparently, in nutrition education. Before you can assess if nutrition information curbs unhealthy eating, you first have to get people to notice the information. And in restaurants, the only location that really matters is the menu.

"You have to look at the menu if you want to select an item or look at the price, and that is the most valuable real estate in the restaurant in terms of getting people's attention," said David Hammond, an associate professor in the School of Public Health and Health Systems at the University of Waterloo in Ontario. He was presenting at the Canadian Public Health Association 2013 Annual Conference, recently held in Ottawa, Ontario.

Encouraging healthier eating in restaurants could play an increasingly important role in fighting obesity, suggested Hammond, because Canadians eat outside the home more often than ever before. The portion sizes and number of calories in those meals is also on the rise, yet few patrons have a notion of the nutritional value of what's sitting on their plates.

That information might be available, in a pamphlet or on a poster, but if it's not on the menu, it rarely gets noticed. "Yes, you can have a poster under the counter, but unless you make it visible, people are not going to go out of their way to access that information," said Hammond.

In Canada, there are no mandatory regulations compelling restaurants to disclose nutrition information on menus (or on menu boards in fast-food chains). British Columbia has a voluntary program, called Informed Dining, but restaurants that sign up only have to provide nutritional data upon request.

A few cities in the United States have mandatory menu labelling regulations, requiring calorie counts be listed next to prices in the same-size font, and the US Food and Drug Administration is considering federal policies. The popular coffee chain Starbucks recently decided to make the change before being required to by law. Starting June 25 , it will post calorie information on

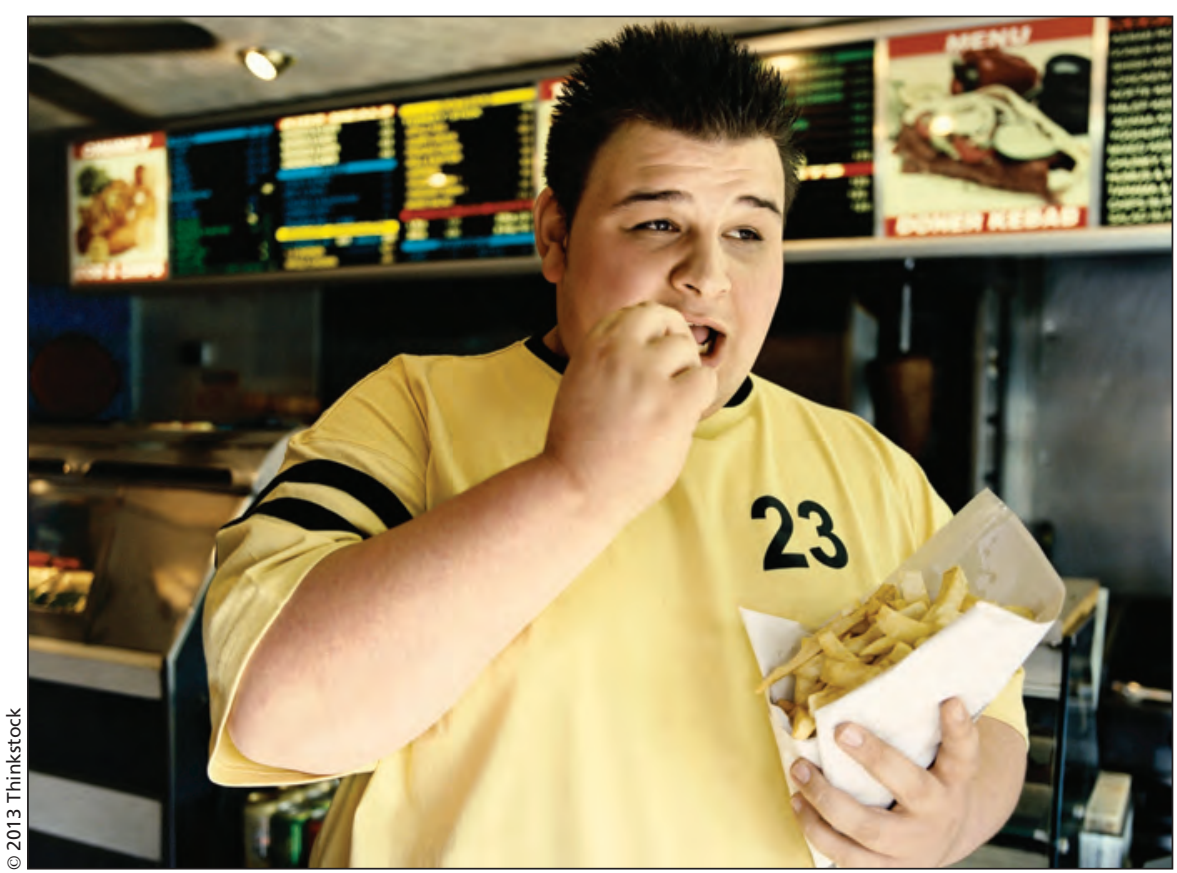

How many calories in those fries? Chances are, the menu board won't tell you.

menu boards in its US locations. Drinks at the chain can range from nearly zero calories to in excess of 600 .

Countrywide regulations are unlikely to be implemented in Canada. According to Health Canada, such matters fall under the purview of provinces and territories. The federal government is, however, involved with provinces and territories in a task group exploring the provision of nutrition information.

"This group is currently examining, in collaboration with industry, experts and researchers, approaches to providing nutrition information in restaurants and food services that could empower Canadians to make more informed food choices when they eat away from home," the agency stated in an email from Leslie Meerburg, a media relations officer.

To compare the availability, awareness and use of nutritional information in restaurants located in areas with different menu labelling policies, Hammond and colleges conducted exit surveys with 2922 patrons in several cities in the US and Canada, including Toronto, Ontario (no policy), Vancouver, BC (voluntary policy) and Seattle, Washington (mandatory policy). The surveys were conducted outside both fast-food chains and fullservice restaurants.
The statistics in a brief summary of the results suggest that putting nutrition information on the menu does indeed get results (the study is currently under review for publication at a journal). More than twice as many survey participants in Seattle (56\%) reported being aware of nutrition information than in Toronto (25\%) and Vancouver (22\%). Greater awareness is also associated with better choices, with $8.4 \%$ of Seattle patrons reporting the nutrition information influenced a healthier meal selection, compared to $1.3 \%$ in Toronto and less than $1 \%$ in Vancouver.

"We are seeing that mandatory policies are associated with greater noticing and greater use of the information," said Hammond. "Right now, we are not seeing any impact of the voluntary policy."

Mandatory menu labelling not only gets noticed and influences food choices, suggested Hammond, but it also forces food outlets to reflect upon their offerings. The shame of having incredibly high calorie counts and sodium levels for all to see could, for instance, move a chain to use healthier oils or less sugar and salt. - Roger Collier, CMAJ

CMAJ 2013. DOI:10.1503/cmaj.109-4524 